\title{
CONTRIBUIÇÕES DE UMA REDE DE COOPERAÇÃO A COOPERATIVAS DE AGRICULTURA FAMILIAR PARA A IMPLEMENTAÇÃO DO PNPB EM SERGIPE: O CASO DA REDE BIODIESEL SERGIPE
}

\section{CONTRIBUTIONS OF A COOPERATION NETWORK FOR FAMILY FARMING COOPERATIVE FOR THE IMPLEMENTATION OF NPPB IN SERGIPE: THE CASE OF SERGIPE BIOFUEL NETWORK}

\author{
Vitor Hugo da Silva Vaz \\ Parque Tecnológico de Sergipe - SE - Brasil \\ Maria Elena Leon Olave \\ Universidade Federal de Sergipe - SE - Brasil
}

\begin{abstract}
Resumo: Os estudos sobre as relações de cooperação entre as empresas é um dos focos centrais quando se aborda as relações de cooperação. Este estudo tem como objetivo analisar como uma rede de cooperação contribuiu para a implantação e consolidação do Programa Nacional de Produção e uso do Biodiesel - PNPB e gerou contribuições às cooperativas de agricultura familiar em Sergipe. O método utilizado na pesquisa foi o estudo de caso único, com base nos relatos de representantes de três cooperativas de agricultura familiar, utilizando entrevistas semiestruturadas. Os resultados mostram que as relações de cooperação apresentaram diversas informações, com destaque para: a compreensão dos objetivos da rede entre as instituições participantes, o estabelecimento de relações formais com grandes instituições, que proporcionou credibilidade, o acesso a novos mercados, a redução de custos e riscos e o estabelecimento de relações sociais as cooperativas.
\end{abstract}

Palavras-chave: Redes. Cooperação. Biodiesel. Agricultura Familiar. Cooperativas.

Abstract: Studies on the relationship between companies is a central focus when discussing cooperative relations. This study aims to analyze how a network of cooperation contributed to the implementation and consolidation of the National Program for Production and Use of Biofuel NPPB and generated contributions to family farming cooperatives in Sergipe. The method used in the research was the single case study, based on reports from representatives of three family agriculture cooperatives using semi-structured interviews. The results show that the cooperation had various information, especially the understanding of the network's objectives between the participating institutions, the establishment of formal relations with large institutions provided credibility, access to new markets, reducing costs and risks and the establishment of social relations cooperatives.

Keywords: Networking. Cooperation, Biofuel. Family Farming. Cooperatives.

\section{Introdução}

De acordo com Doz e Hamel (2000 apud GARCIA, 2008), as redes ou networks são sistemas organizacionais crescentes na medida em que um conjunto 
de empresas procura por estratégias que sejam, ao mesmo tempo, flexíveis e efetivas para a obtenção de um melhor resultado global.

Para Castells (1999), as redes são componentes fundamentais para o desenvolvimento das organizações e, de forma geral, sua formação e expansão por toda a economia global são decorrentes do poder da informação propiciada pela necessidade de se introduzir tecnologias nos sistemas produtivos.

De acordo com Aragão, Lopes e Alves Junior (2010), do ponto de vista das empresas, o desejo de cooperação em rede resulta de duas premissas: a primeira advém da ideia de sinergia, a qual o todo é sempre maior do que a soma das partes; a segunda é de que os benefícios resultantes das relações entre os integrantes da rede são do tipo ganha-ganha, isto é, seguem sempre orientadas por decisões conjuntas, de maneira que os benefícios ou insucessos são distribuídos entre todos.

Para contribuir com o desenvolvimento de uma política pública para a produção de biodiesel no Nordeste, especificamente no Estado de Sergipe, no ano de 2007, foi criada a Rede Biodiesel Sergipe. A Rede de Cooperação em questão teve como finalidade desenvolver a produção de matéria-prima para biodiesel no estado com a participação efetiva da agricultura familiar.

O biodiesel é um biocombustível derivado de biomassa renovável para uso em motores a combustão interna com ignição por compressão ou, conforme regulamento, para geração de outro tipo de energia que possa substituir parcial ou totalmente o combustível de origem fóssil (BRASIL, 2005a).

A busca por alternativas renováveis e menos poluentes tende a conferir um importante papel para a agricultura, seja pela produção de matérias-primas ou pelo aproveitamento de resíduos de natureza energética (VIEIRA, 2006).

A regulamentação da produção de biodiesel no Brasil deu-se pela Lei 11.097 de 2005, que introduziu O PNPB, e estabeleceu as condições para comercialização, produção e uso do biodiesel, com a obrigatoriedade da participação dos agricultores familiares e/ou suas representações (cooperativas, associaçõ̃es e federações) na cadeia de suprimento (ABRAMOVAY; MAGALHÃES, 2007).

Porém, os primeiros seis meses em que o biodiesel passou a compor todo o diesel distribuído no Brasil, a partir de janeiro de 2008, foram marcados por uma série de críticas ao PNPB, tanto em seu formato constitutivo como a respeito de possíveis impactos negativos sobre a segurança alimentar.

Uma das principais críticas ao PNPB relaciona-se à ambição social de incluir a agricultura familiar, principalmente a do Nordeste, à cadeia produtiva. Segundo os críticos, os agricultores familiares do Nordeste teriam sucumbido diante de práticas tradicionais e do predomínio da oferta de matéria-prima vinda do CentroSul do país (CAMPOS; CARMELO, 2009). A busca por soluções para que a agricultura familiar atenda à demanda da indústria de biodiesel do País, de certa forma, tem se revelado em imbricadas redes de cooperação (ABRAMOVAY; MAGALHÃES, 2007). 
A Rede Biodiesel em Sergipe foi formada por organizações ligadas à agricultura familiar, movimentos sociais, instituições de pesquisa, produtores de biodiesel e o governo do estado, no formato de rede de cooperação. A rede em questão surgiu com a finalidade de propor soluções aos entraves existentes nessa cadeia produtiva e para acelerar a resposta às demandas crescentes de biodiesel, com a participação das famílias de agricultores.

Em função do contexto apresentado, o presente artigo tem como objetivo analisar como a rede de cooperação contribuiu para a implantação e consolidação do programa de produção de matéria-prima para biodiesel em Sergipe e quais os benefícios gerados às cooperativas de agricultura familiar. Especificamente, o estudo pretende verificar quais os motivos que levaram as cooperativas de agricultura familiar a participar da rede estudada, quais os tipos de relações estabelecidas e identificar os benefícios gerados por meio das relações de cooperação em rede.

Para alcançar o objetivo proposto será apresentada uma revisão teórica sobre o processo de formação de redes de cooperação e os benefícios gerados às organizações participantes. Em seguida, apresentar-se-á uma explanação da metodologia adotada no trabalho. Logo após, será realizada uma breve apresentação do Programa Nacional de Produção e uso do Biodiesel - PNPB e da Rede Biodiesel Sergipe. Por fim, serão apresentados os resultados das pesquisas realizadas com representantes das cooperativas de agricultura familiar participantes da rede estudada, seguida da comparação entre os resultados e as considerações finais.

\section{As Redes de Cooperação}

A literatura sobre a cooperação é rica em teoria e diversificada em suas raízes acadêmicas. Na verdade, a cooperação é um tema de interesse em disciplinas como economia, sociologia, antropologia, psicologia e ciência política, bem como em comportamento organizacional, teoria de organização e gestão estratégica (SMITH; CARROLL; ASHFORD, 1995).

Ring e Van de Ven (1994) defendem a definição de uma cooperação mais dinâmica na qual destacam uma disposição dos indivíduos para continuar em relações de cooperação. Os autores destacam que as relações de cooperação são mecanismos socialmente inventados para a ação coletiva, que são continuamente moldados e reestruturados por ações e interpretações simbólicas das partes envolvidas.

As redes de cooperação podem surgir a partir de uma ampla variedade de condições iniciais, como laços de amizade preexistentes, o mandato institucional, ou de dependência de recursos e busca por uma organização para acessar recursos necessários (RING; VAN DE VEN, 1994).

Segundo Rumyantseva e Tretyak (2003), os conceitos e objetivos das redes de cooperação estão relacionados aos componentes que devem ser agrupados e reagrupados para responder às variações competitivas para enfrentar às pressões 
do mercado. Nesse contexto, as redes de cooperação são atividades de negócios realizados por meio de processos de colaboração para gerar vendas e lucros.

Embora as redes de empresas sejam um fenômeno, comumente entendido, de vida organizacional, nem sempre está claro exatamente o que os estudiosos organizacionais estão falando quando usam o termo (PROVAN; FISH; SYDOW, 2007). Dessa forma, faz-se necessário estudos mais aprofundados sobre os aspectos relacionados à formação, às tipologias, ao desenvolvimento e aos benefícios gerados pelas redes de cooperação.

De acordo com Ring e Van de Ven (1994), as redes de cooperação podem surgir a partir de uma ampla variedade de condições iniciais, como laços de amizade preexistentes, o mandato institucional, seguindo a teoria da dependência de recursos, entre outras.

Dentre os estudos já realizados sobre os motivos da formação de redes de cooperação, pode-se destacar os de Oliver (1990), que atribui seis elementos responsáveis pela formação de redes, sendo elas: necessidade, assimetria, reciprocidade de cooperação, eficiência estabilidade e legitimidade. A especificação dos elementos descritos anteriormente é definida no Quadro 1 a seguir.

Quadro 1. Elementos responsáveis pela formação das redes interorganizacionais

\begin{tabular}{|l|l|}
\hline \multicolumn{1}{|c|}{ Elementos } & \multicolumn{1}{c|}{ Definições } \\
\hline Necessidade & $\begin{array}{l}\text { Quando uma organização estabelece elos com outras organizações por } \\
\text { necessidade. }\end{array}$ \\
\hline Assimetria & $\begin{array}{l}\text { Quando as relações interorganizacionais são induzidas pelo potencial } \\
\text { exercício de poder de uma organização sobre outra. }\end{array}$ \\
\hline Reciprocidade & Ocorrem com o propósito de buscar interesses e objetivos comuns. \\
\hline Eficiência & Busca um melhor desempenho na eficiência da organização. \\
\hline Estabilidade & $\begin{array}{l}\text { Pode ser caracterizada como uma resposta a grande incerteza existente em } \\
\text { um ambiente. }\end{array}$ \\
\hline Legitimidade & Justificar a existência das organizações. \\
\hline
\end{tabular}

Fonte: Baseado em Oliver (1990).

De acordo com Oliver (1990), os fatores relacionados anteriormente são as principais motivações que explicam e/ou motivam as organizações a estabelecerem as relações de cooperação em rede. Embora sejam elementos explicados de forma isolada, geralmente, os elementos podem ser identificados simultaneamente nas redes de empresas. Entretanto, de acordo com Bachmann e Witteloostuijn (2006), a depender das oportunidades e ameaças envolvidas no interesse, bem como os custos e benefícios das diferentes opções que uma cooperação em rede proporciona, uma empresa deve selecionar estrategicamente o modo de transação que considera "ideal". Dessa forma, é importante estudar as diferentes características das relações de cooperação que ocorrem em uma rede. 


\subsection{Características das Relações de Cooperação em Rede}

A variedade de controles que as empresas utilizam como forma de estruturar as relações com outras empresas é uma questão crucial, pois se trata do tipo de comunicação que a organização pode utilizar. Nessa perspectiva, é necessário conhecer o tipo de cooperação que será estabelecida entre as empresas, tendo em vista que a conexão entre os parceiros pode influenciar as relações em rede (SMITH; CARROLL; ASHFORD, 1995).

Smith, Carroll e Ashford (1995) constataram que as organizações ligadas verticalmente a grupos e outras organizações podem cooperar em um nível superior e/ou um nível de subordinação. Já as partes das organizações ligadas horizontalmente podem cooperar com trabalhos envolvidos em uma tarefa comum ou, até mesmo, com concorrentes de uma única indústria.

A cooperação envolvendo ligações verticais será diferente da que envolve ligações horizontais, principalmente em termos de interdependência. Nesse caso, a interdependência é estabelecida por relações de cooperação que podem ser caracterizadas como formais e informais.

Segundo Chetty e Agndal (2007), a cooperação formal permite o processo de seleção das organizações e credencia a criação da rede para uma finalidade específica, ou com base em relacionamentos anteriormente informais que foram transformados em relações formalizadas. São exemplos de redes de cooperação formalizadas as associações industriais, grupos de interesses especiais e grupos de exportação.

As relações em rede podem se desenvolver com interesses compartilhados e alavancados, sobretudo, na confiança entre os atores. Na cooperação em rede informal, os atores são vistos como incorporados em contextos em que dependem dos recursos controlados e atividades realizadas por outros atores. A rede é constituída de títulos de uma empresa focal para com outros atores, como compradores, fornecedores e concorrentes. Os laços entre os recursos são controlados pelos atores na rede e as ligações entre as atividades que se desenvolvem (CHETTY; AGNDAL, 2007). No quadro 2 é possível ver um resumo das características que norteiam as relações formais e informais existentes nas relações de cooperação em redes de empresas.

Quadro 2. Características da relações de cooperação em rede

\begin{tabular}{|l|l|}
\hline \multicolumn{1}{|c|}{ Tipos } & \multicolumn{1}{|c|}{ Características } \\
\hline Redes formais & $\begin{array}{l}\text { A dimensão contratual. Algumas redes são formalizadas por meio de } \\
\text { termos contratuais, que estabelecem regras de conduta entre os atores. } \\
\text { Redes como as alianças estratégicas, os consórcios de exportação, as joint } \\
\text { venturese as franquias são exemplos de redes fortemente formalizadas. }\end{array}$ \\
\hline $\begin{array}{l}\text { Redes } \\
\text { informais }\end{array}$ & $\begin{array}{l}\text { A dimensão da conivência. Permitem os encontros informais entre os } \\
\text { atores econômicos (empresas, organizações profissionais, instituições, } \\
\text { universidades, associações etc.), portadores de preocupações semelhantes. }\end{array}$ \\
\hline
\end{tabular}

Fonte: Com base em Balestrin e Vargas (2002). 
Ring e Van de Ven (1994) destacam que uma das grandes vantagens do processo de cooperação é manter o equilíbrio entre os processos formais e informais. Todavia, os autores ressaltam que as relações informais cada vez mais são substituídas por contratos legais por causa da capacidade das partes em contar com a confiança que decorre de uma negociação justa anterior.

Além dos tipos de relação, o que se espera das relações de cooperação em rede são os resultados que o arranjo de empresas podem representar às organizações parceiras. Nesse caso, os ganhos proporcionados pela cooperação entre empresas em redes representam um dos principais focos de atenção dos estudos sobre as relações de cooperação (BALESTRIN; VERSCHOORE; REYES JUNIOR, 2010).

\subsection{Benefícios proporcionados pela Cooperação em Redes}

De acordo com Verschoore e Balestrin (2008), os resultados da cooperação de empresas em redes representam um dos principais focos de atenção dos estudos sobre as relações em redes de empresas.

Nesse sentido, Balestrin e Vargas (2002) buscaram evidências teóricas para sustentar a tese de que as redes de cooperação podem facilitar o desenvolvimento de pequenas e médias empresas em um estudo no segmento têxtil do Sul do Brasil. Os resultados exploratórios revelaram que a configuração em rede possibilitou às empresas certos benefícios, como aprendizagem coletiva, poder de barganha junto a fornecedores, acesso a novos mercados, redução de custos de transação, melhoria nos processos de produção e economias de escala, escopo e especialização.

Barbosa e Souza (2011) analisaram as estratégias empresariais pautadas pela edificação de redes de cooperação nos dois maiores polos de fabricação de calçados do Estado de São Paulo: Franca, especializado em calçados masculinos, e Birigui, especializado em calçados infantis. Os autores identificaram que nos dois casos a cooperação representou grande diferencial da estratégia empresarial no enfrentamento dos efeitos do processo de reestruturação produtiva no setor calçadista da região.

Castro, Bulgacov e Hoffmann (2011) analisaram os resultados gerados por uma rede de cooperação do segmento varejista de materiais de construção e constataram que houve certa dificuldade a partir do momento em que não existiu a cooperação entre as empresas.

Bortolaso, Verschoore e Antunes Junior (2012) realizaram um estudo do desenvolvimento de 12 redes de pequenas e médias empresas no Rio Grande do Sul e apontaram como resultado um desenvolvimento equilibrado entre as organizações.

Alves et al. (2013), por exemplo, analisaram as principais publicações internacionais sobre o processo de cooperação em rede, tendo como elementos principais a confiança, a aprendizagem e o conhecimento. Foi diagnosticado que o 
processo de cooperação contribuiu para dar agilidade, flexibilidade e competitividade frente às variações do ambiente no qual as redes estão inseridas.

O que se evidencia, a partir dos estudos apresentados, é a grande contribuição atribuída às relações de cooperação em rede. Nesse caso, estar em rede permite potenciar as competências individuais e aumentar as oportunidades coletivas (OLIVEIRA; REZENDE; CARVALHO, 2010).

De acordo com Verschoore e Balestrin (2008), existem cinco elementos que representam ganhos competitivos considerados como benefícios proporcionados pelas redes de cooperação, que são: ganhos de escala e de poder de mercado, acesso a soluções e capacitação, aprendizagem e inovação, redução de custos e riscos e relações sociais. Suas definições são apresentadas no Quadro 3.

Quadro 3. Elementos que representam benefícios em relações de cooperação

\begin{tabular}{|l|l|}
\hline \multicolumn{1}{|c|}{ Elementos } & \multicolumn{1}{c|}{ Definição } \\
\hline $\begin{array}{l}\text { Escala e Poder de } \\
\text { Mercado }\end{array}$ & $\begin{array}{l}\text { Benefícios obtidos em decorrência do crescimento do número de } \\
\text { associados da rede. } \\
\text { Quanto maior o número de empresas, maior a capacidade da rede em } \\
\text { obter ganhos de escala e poder de mercado. }\end{array}$ \\
\hline $\begin{array}{l}\text { Acesso a Soluções e } \\
\text { Capacitação }\end{array}$ & $\begin{array}{l}\text { Os serviços, os produtos e a infraestrutura disponibilizados pela rede para } \\
\text { o desenvolvimento de seus associados. }\end{array}$ \\
\hline $\begin{array}{l}\text { Aprendizagem e } \\
\text { Inovação }\end{array}$ & $\begin{array}{l}\text { O compartilhamento de ideias e de experiências entre os associados e as } \\
\text { ações de cunho inovador desenvolvido em conjunto pelos participantes. }\end{array}$ \\
\hline $\begin{array}{l}\text { Redução de } \\
\text { Custos e Riscos }\end{array}$ & $\begin{array}{l}\text { A vantagem de dividir entre os associados os custos e os riscos de } \\
\text { determinadas ações e investimentos comuns aos participantes. }\end{array}$ \\
\hline $\begin{array}{l}\text { Relações } \\
\text { Sociais }\end{array}$ & $\begin{array}{l}\text { O aprofundamento das relações entre os indivíduos, o crescimento do } \\
\text { sentimento de família e a evolução das relações do grupo para além } \\
\text { daquelas puramente econômicas. }\end{array}$ \\
\hline
\end{tabular}

Fonte: Com base em Verschoore e Balestrin (2008).

Os elementos apresentados nas seções anteriores sobre a formação, tipos de relações estabelecidas e benefícios gerados pelas redes de cooperação serviram como base para a elaboração dos procedimentos metodológicos adotados nesta pesquisa e são apresentados na seção a seguir.

\section{Procedimentos Metodológicos}

O estudo pode ser considerado qualitativo, pois é fundamentalmente interpretativo e permite ao pesquisador ter uma visão holística do fenômeno (CRESWELL, 2002). Também pode ser considerado um estudo exploratório e descritivo. O estudo é exploratório, pois busca informações sobre as ações de cooperação para consolidação do Programa de Biodiesel em Sergipe, e descritivo, pois caracteriza e descreve as cooperativas inclusas no programa em questão, além das formas de cooperação e os benefícios gerados às cooperativas produtoras de biodiesel em Sergipe. A estratégia de pesquisa adotada é a de estudo de casos que, de acordo com Yin (2010), representa a estratégia preferida quando se colocam questões do tipo "como" e "por que", no qual o pesquisador tem pouco 
controle e quando o foco se encontra em fenômenos contemporâneos inseridos em algum contexto da vida real.

A pesquisa em questão é considerada de corte transversal, pois as informações que foram coletadas em um único momento junto aos representantes das instituições participantes da rede. Segundo Newman (1997), as pesquisas de corte transversal podem ser exploratórias, descritivas e explanatórias, mas é mais consistente com a abordagem descritiva.

O tipo de estudo usado foi o estudo de caso único, que considera a análise de um fenômeno contemporâneo e que, também, representa um caso extremo e revelador (YIN, 2010). De acordo com Stake (1994), em alguns casos, os estudos de caso único apresentam mais confiabilidade que os estudos de casos múltiplos, pois permitem uma compreensão mais profunda da ocorrência de um fenômeno. Segundo o autor, os estudos de caso único proporcionam a oportunidade de outros pesquisadores, em um momento no futuro, usufruírem do estudo que até então não havia sido explorado e, posteriormente, o estudo em questão pode ser comparado com situações semelhantes.

De acordo com Alves-Mazzotti (2006), um caso é uma entidade complexa operando dentro de vários contextos - físico, econômico, ético, estético e outros e, devido a sua singularidade, possui subunidades, diferentes grupos, situações, etc. Desta forma, é necessária a compreensão holística do caso para o exame mais detalhado dessas complexidades.

O caso que foi analisado é da Rede Biodiesel Sergipe, que é a única rede no estado a realizar ações para a estruturação da produção de matéria-prima para biodiesel em Sergipe e na qual foi observada a existência de governança.

A coleta das evidências ocorreu por meio de entrevistas semiestruturadas que, de acordo com Yin (2010), é um dos principais métodos de coleta de informações em um estudo de caso. Saunders, Lewis e Thornill (2007) destacam que as entrevistas semiestruturadas podem ser usadas para explorar e explicar temas que surgiram a partir do uso de um questionário.

Entrevistas semiestruturadas ou em profundidade, podem também ser utilizadas como um meio para validar os resultados da utilização de questionários. Também fornece a oportunidade de "sondar" respostas, nas quais os entrevistados podem explicar, ou construí-las (YIN, 2010). Podem, também, levar a discussão para as áreas que o pesquisador não tinha considerado anteriormente e, consequentemente, essa discussão contribui para a profundidade na pesquisa.

Com relação à escolha dos casos, segundo Stake (1994), mesmo que um estudo de caso seja único, a seleção do caso deve possibilitar uma provável replicação futura. Dessa forma, o pesquisador deve examinar os vários interesses no fenômeno, a seleção do caso que tenha alguma tipicidade, mas sempre se inclinando para aqueles casos que podem oferecer oportunidades de aprendizado. Nesse sentido, a Rede Biodiesel Sergipe foi escolhida como a unidade de análise do estudo, e as subunidades de análise foram as instituições participantes da rede. 
Assim, foram realizadas entrevistas com os representantes de três cooperativas de agricultura familiar. Essas instituições foram escolhidas levando-se em consideração que apenas as três cooperativas participaram do programa de produção de matéria-prima para biodiesel em Sergipe.

Os representantes escolhidos para participar do estudo foram os presidentes das cooperativas COOPERAFIR e COOPATSUL e um técnico agrícola da COOPRASE. Os representantes foram escolhidos por serem os responsáveis das instituições na rede de cooperação e nas parcerias firmadas para 0 desenvolvimento do programa de produção de biodiesel em Sergipe e, assim, apresentar informações mais detalhadas sobre as relações de cooperação em rede.

As categorias analíticas do estudo foram definidas a partir dos objetivos e da revisão teórica sobre o tema redes de cooperação. No quadro 04, pode-se observar as categorias utilizadas no estudo, com os respectivos elementos de análise.

Quadro 4. Categorias analíticas e elementos de análise

\begin{tabular}{|l|l|}
\hline \multicolumn{1}{|c|}{ Categorias Analíticas } & \multicolumn{1}{c|}{ Elementos de Análise } \\
\hline $\begin{array}{l}\text { Formação da rede de cooperação (OLIVER, } \\
\text { 1990). }\end{array}$ & $\begin{array}{l}\text { Motivo (s) para participar da rede; Iniciativa para } \\
\text { criar a rede; Primeiros participantes; Objetivo da } \\
\text { rede; Estrutura de governança da rede; Gestão da } \\
\text { rede }\end{array}$ \\
\hline $\begin{array}{l}\text { Formas de cooperação (SMITH; CARROLL; } \\
\text { ASHFORD, 1995). }\end{array}$ & Formais; Informais \\
\hline $\begin{array}{l}\text { Benefícios (VERSCHOORE; BALESTRIN, } \\
\text { 2008). }\end{array}$ & $\begin{array}{l}\text { Escala e Poder de Mercado; Acesso a Soluções e } \\
\text { Capacitação; Aprendizagem e Inovação; Redução } \\
\text { de Custos e Riscos; Relações Sociais }\end{array}$ \\
\hline
\end{tabular}

Elaborado pelo autor com base nas teorias adotadas no estudo.

Com relação à confiabilidade das informações, Yin (2010) diz que, em uma pesquisa, existe a necessidade de se desenvolver um banco de dados. Nesse viés, para garantir a segurança das informações, foi realizada a gravação das entrevistas, que permitiu o registro preciso e imparcial da informação, além de possibilitar que outros pesquisadores possam utilizar as informações armazenadas.

Na seção a seguir, será feita uma breve apresentação do PNPB e o caso Rede Biodiesel Sergipe, que servirá como base para a coleta de informações que foram utilizadas na pesquisa. Para a análise do caso, foi realizada, inicialmente, a descrição das instituições participantes da Rede Biodiesel Sergipe de forma individual, seguida da análise comparativa (EISENHARDT, 1989).

A comparação dos resultados permitirá o fortalecimento da fundamentação da teoria por meio da comparação das respostas apresentadas. Na descrição das subunidades, é apresentado um breve histórico sobre as organizações estudadas com base nos relatos apresentados pelos seus representantes. 


\section{O Programa Nacional de Produção e uso do Biodiesel - PNPB}

No dia 13 de janeiro de 2005, o PNPB foi instituído pela Lei no 11.097, que estabeleceu a adição de $2 \%$ de Biodiesel a todo o diesel do país a partir de janeiro de 2008 (BRASIL, 2005). Sendo que, após oito anos daquela data, o percentual obrigatório passaria a ser $5 \%$.

A Lei no 11.097/2005 prevê a possibilidade de antecipação da aplicação destes percentuais de mistura de Biodiesel ao diesel por meio de resoluções do Conselho Nacional de Política Energética - CNPE, observados os seguintes critérios:

- A disponibilidade de oferta de matéria-prima e a capacidade industrial para produção de Biodiesel;

- A participação da agricultura familiar na oferta de matérias-primas;

- A redução das desigualdades regionais;

- O desempenho dos motores com a utilização do combustível; e

- As políticas industriais e de inovação tecnológica.

O PNPB foi criado com o objetivo de implementar de forma sustentável, tanto técnica como econômica, a produção e uso do biodiesel, com enfoque na inclusão social e no desenvolvimento regional, via geração de emprego e renda (BRASIL, 2009). As principais diretrizes do programa são:

- Implantar um programa sustentável, promovendo a inclusão social;

- Garantir preços competitivos, qualidade e suprimento;

- Produzir o biodiesel a partir de diferentes fontes oleaginosas fortalecendo as potencialidades regionais para a produção de matéria-prima.

O PNPB representa um mercado que começa a se formar a partir de uma intervenção governamental que estimula a participação de agricultores familiares em sua matriz produtiva e que pretende incentivar o uso de matérias-primas até então pouco empregadas, como é o caso do girassol no nordeste (ABRAMOVAY E MAGALHÃES, 2007).

O componente de inclusão social do programa foi estabelecido por meio do modelo tributário, visando favorecer a participação da agricultura familiar e desenvolver as regiões Norte, Nordeste e o Semiárido (BRASIL, 2005b). O mecanismo de controle do benefício tributário como incentivo para atingir ao propósito de integrar agricultores familiares à oferta de biocombustíveis é o Selo Combustível Social, que possibilita redução de Programas de Integração Social (PIS) e Contribuição para Financiamento da Seguridade Social (COFINS) do preço de venda do biodiesel pelas empresas que o obtiverem.

A obtenção do Selo Combustível Social pelas indústrias produtoras de biodiesel se dá com a aquisição de matéria-prima da agricultura familiar de acordo com os percentuais estabelecidos em cada região do Brasil e conforme a Portaria n 60 de 2012 (BRASIL, 2012). 
A preocupação social do Governo Federal levou ao desenvolvimento de ações estratégicas nos estados visando ao desenvolvimento do agronegócio do biodiesel, especialmente no Nordeste, em benefício da agricultura familiar (GONÇALVES; EVANGELISTA, 2008).

De acordo com Abramovay e Magalhães (2007), a busca de soluções para que a agricultura familiar atenda à demanda da indústria de biodiesel do País de certa forma tem se revelado em imbricadas redes de cooperação. Em Sergipe, foi criada a Rede Biodiesel Sergipe com a finalidade de desenvolver o PNPB no Estado.

\subsection{A Rede Biodiesel Sergipe}

A Rede Biodiesel Sergipe foi formada por diversos agentes e instituições públicas e privadas, entre elas as Secretarias de Estado do Desenvolvimento Econômico da Ciência e Tecnológica - SEDETEC, Secretária de Estado do Planejamento - SEPLAN e Secretaria de Agricultura - SEAGRI, entidades de pesquisa como Embrapa Tabuleiros Costeiros, representantes dos agricultores e agricultoras (Federação dos Trabalhadores na Agricultura de Sergipe - FETASE) e movimentos sociais (Movimento dos Trabalhadores Sem Terra - MST) cooperativas de agricultura familiar e Petrobras (Unidade Sergipe-Alagoas UN/SEAL e, posteriormente, Petrobras Biocombustível, a partir de 2009).

As instituições se uniram, em 2007, com o intuito de estruturar um programa para o desenvolvimento da cadeia produtiva do biodiesel no estado, intitulado: Programa de Biodiesel em Sergipe - PROBIOSE.

A Rede Biodiesel Sergipe assume um papel diferenciado que inclui levantar e organizar as demandas dos potenciais produtores rurais, de suas organizações profissionais e da indústria para a ciência e, ao mesmo tempo, buscando, nas pesquisas e suas entidades, propostas de melhorias e a viabilização de inovações tecnológicas e sócio-organizacionais para a produção de biodiesel.

É importante destacar que a produção agrícola em Sergipe era um segmento que se encontrava desorganizado e com fortes necessidades de aprendizagem, e que precisava ser desenvolvido para atender aos termos contratuais exigidos pela indústria de biodiesel (VITAL BRAZIL et al., 2008). Na figura 1, é possível ver cada um dos papéis assumidos pelas instituições participantes da Rede Biodiesel Sergipe na construção da proposta do programa de produção de biodiesel no Estado. 


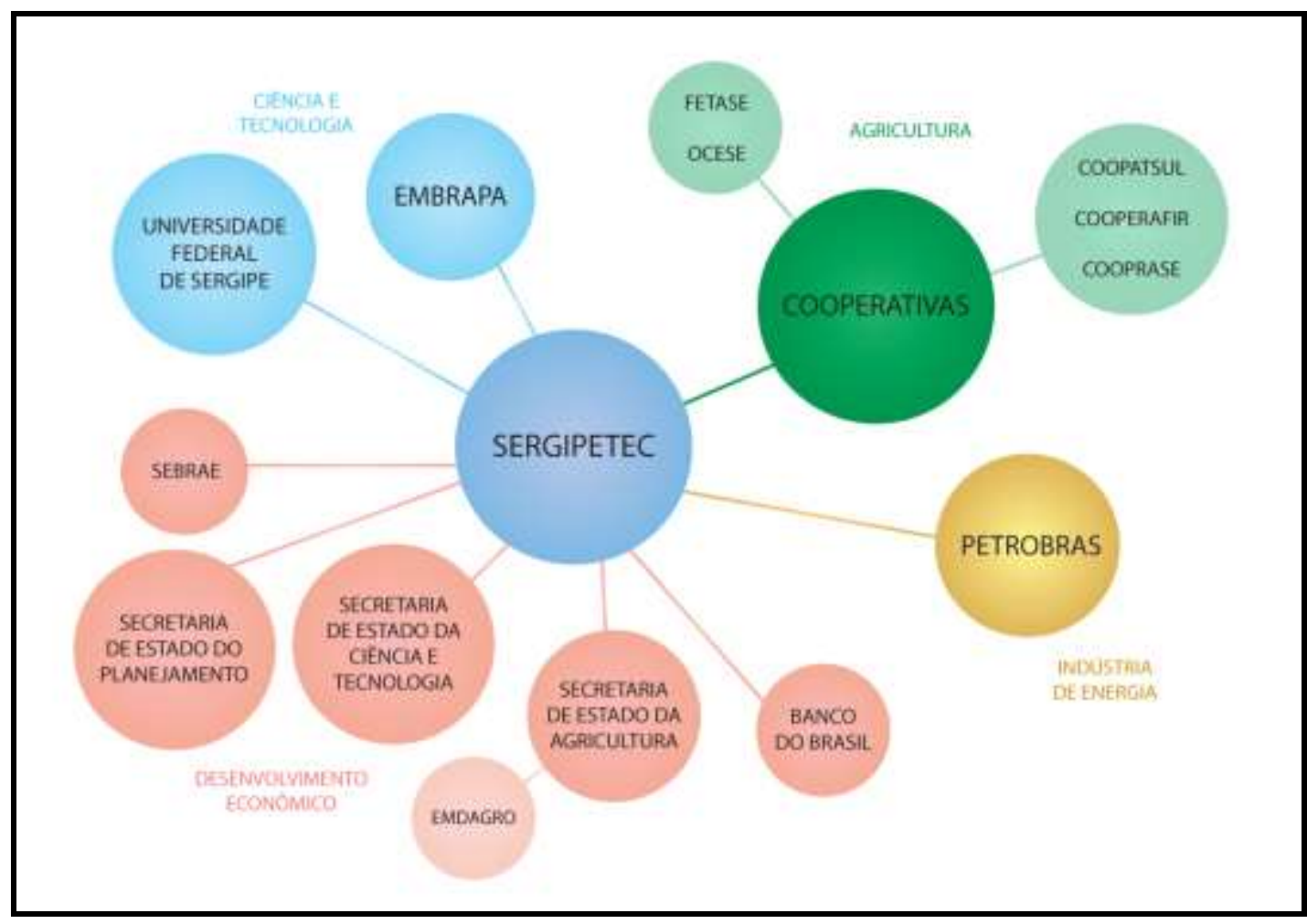

Figura 1. Estrutura da Rede Biodiesel Sergipe

Fonte: Elaboração Própria (2014).

Apesar da grande quantidade de instituições presentes na Rede Biodiesel Sergipe, as ações de produção agrícola estavam centradas nas cooperativas. Nesse caso, as cooperativas foram as instituições que tinham a função de negociar diretamente os contratos de compra da produção agrícola. Assim, compunham a parte de execução da produção do biodiesel e se alinharam em um processo de cooperação que gerou os resultados apresentados a seguir.

\subsection{As Instituições Cooperativas participantes da Rede}

Conforme visto anteriormente, a Rede Biodiesel Sergipe possuiu em sua estrutura três organizações cooperativas que produziram matéria-prima para 0 biodiesel. As cooperativas foram: Cooperativa de Produção, Comercialização e Prestação de Serviços dos Agricultores Familiares de Indiaroba e Região COOPERAFIR; Cooperativa Regional dos Assentados de Reforma Agrária do Sertão de Sergipe Ltda. - COOPRASE; e Cooperativa dos Produtores Agrícolas do Território Sul de Sergipe - COOPATSUL.

A COOPERAFIR é um órgão associativo composto por trabalhadores rurais, pequenos agricultores e trabalhadores de outras categorias, que estimula as atividades profissionais a serviço das comunidades rurais da área de atuação da cooperativa. Foi fundada no dia 16 de setembro de 2007, com personalidade jurídica de direito privado, sem fins lucrativos, de duração por tempo indeterminado. 
A COOPERAFIR possui 580 cooperados com atividades direcionadas à produção e comercialização de gêneros alimentícios. Para contribuir com o desenvolvimento da agricultura familiar e dos municípios nos quais atua, a cooperativa estimula a produção local e desenvolve atividades de capacitação, captação de recursos, desenvolvimento da atividade rural, entre outras.

O presidente da instituição no período de 2007 ao início de 2012 foi o senhor Adinaldo do Nascimento Santos, também assentado da reforma agrária e cooperado, que vivenciou as atividades da rede de cooperação para produção de biodiesel em Sergipe, sendo o detentor do conhecimento de todo o processo das relações estabelecidas com as instituições que faziam parte da rede de cooperação, além de acompanhar os impactos que a relação em rede gerou.

Já a COOPRASE é uma sociedade civil sem fins lucrativos, composto por trabalhadores rurais, pequenos agricultores e trabalhadores de outras categorias enquanto estiverem exercendo as suas atividades profissionais a serviço das comunidades rurais da área de atuação do Centro; com personalidade jurídica de direito privado, sem fins lucrativos, de duração por tempo indeterminado, com sede no Projeto de Assentamento Jacaré Curituba - CEP 49.810-000 - Zona Rural - Poço Redondo/SE, e área de atuação em todo o Estado de Sergipe. Para atingir seus objetivos, a Cooperativa realiza parcerias com empresas do setor privado e com entidades públicas municipais, estaduais, federais, universidades e com ONG's nacionais e internacionais, mediante convênios e/ou contratos ou outras formas jurídicas de cooperação. O presidente da instituição é o senhor João Gomes da Silva, mais conhecido em sua comunidade como João Neguinho, que exerce o cargo na COOPRASE desde a sua fundação. $O$ presidente sugeriu que fosse entrevistado o senhor Lucas de Oliveira Cunha, que, além de engenheiro agrônomo da cooperativa, era o responsável da cooperativa com relação ao acompanhamento de todo o processo de formação de rede e execução das atividades planejadas pelas instituições para consolidação do programa de biodiesel em Sergipe.

Por fim, a COOPATSUL foi constituída no dia 21 de dezembro de 2007 e rege-se pelos valores e princípios do cooperativismo, pelas disposições legais, pelas diretrizes de autogestão de seu estatuto. A sede da cooperativa está localizada na Avenida Josias Carvalho, $\mathrm{n}^{\circ}$ 89, no centro do Município de Salgado.

De acordo com o presidente da cooperativa, em 2008, foram realizadas reuniões nas quais se produziu um diagnóstico prévio do interesse dos agricultores familiares e assentados da reforma agrária em produzirem oleaginosas para biodiesel. O diagnóstico apontou um potencial de 300 famílias que se predispuseram à produção de, pelo menos, de 01 hectare de oleaginosas junto com a cultura de alimentos tradicionais na região, como laranja, maracujá, milho e feijão. Em sua área de atuação, a COOPATSUL cadastrou 97 famílias, com a perspectiva de chegar a 300 famílias, visando fornecer grãos à Petrobras. Essas famílias foram identificadas pelas associações ligadas aos assentados e agricultores familiares de três municípios distribuídos no Território do Sul Sergipano. 


\section{Resultados da Pesquisa}

O Quadro 5 apresenta um resumo da categoria formação da rede das três instituições e os seus respectivos elementos de análise: Motivos para participar da rede; Iniciativa para formação da rede; Instituições participantes; Objetivos da rede; Governança da rede; e Instituição responsável pela gestão da rede.

Quadro 5. Resumo da categoria formação da rede

\begin{tabular}{|c|c|c|c|}
\hline Elementos & COOPERAFIR & COOPRASE & COOPATSUL \\
\hline $\begin{array}{l}\text { Motivos para } \\
\text { participar }\end{array}$ & $\begin{array}{l}\text { Impulsionar a produção } \\
\text { dos agricultores da } \\
\text { região }\end{array}$ & $\begin{array}{l}\text { Desenvolvimento da } \\
\text { agricultura familiar }\end{array}$ & $\begin{array}{l}\text { Benefícios aos } \\
\text { agricultores familiares; }\end{array}$ \\
\hline Iniciativa & SERGIPETEC & SERGIPETEC & SERGIPETEC \\
\hline $\begin{array}{l}\text { Instituições } \\
\text { participantes }\end{array}$ & $\begin{array}{l}\text { FETASE, Emdagro, } \\
\text { Secretaria de Estado da } \\
\text { Agricultura, } \\
\text { SERGIPTEC, Sebrae, } \\
\text { Banco do Nordeste, } \\
\text { Banco do Brasil, } \\
\text { Banese, UFS, Embrapa, } \\
\text { e outras duas } \\
\text { Cooperativas. }\end{array}$ & $\begin{array}{l}\text { SERGIPETEC, Petrobras } \\
\text { Biocombustível, } \\
\text { Embrapa, Endagro, } \\
\text { COOPRASE, } \\
\text { COOPERAFIR, MST, } \\
\text { Banco do Brasil, e } \\
\text { SEBRAE. }\end{array}$ & $\begin{array}{l}\text { Governo do Estado, a } \\
\text { Petrobras, o } \\
\text { SERGIPETEC, o Bando } \\
\text { do Nordeste, o Banco } \\
\text { do Brasil, a COOPRASE } \\
\text { e a COOPERAFIR. }\end{array}$ \\
\hline Objetivos & $\begin{array}{l}\text { Integrar a agricultura } \\
\text { familiar à produção de } \\
\text { biodiesel }\end{array}$ & $\begin{array}{l}\text { Implementar e } \\
\text { fortalecer o PNPB no } \\
\text { estado. }\end{array}$ & $\begin{array}{l}\text { Fortalecer a agricultura } \\
\text { familiar e atender a } \\
\text { Petrobras quanto à } \\
\text { produção. }\end{array}$ \\
\hline $\begin{array}{l}\text { Governança da } \\
\text { rede }\end{array}$ & $\begin{array}{l}\text { SERGIPETEC a } \\
\text { organização central; } \\
\text { Embrapa: orientação a } \\
\text { agricultores; } \\
\text { COOPRASE: assistência } \\
\text { técnica; e } \\
\text { Banco do Brasil: } \\
\text { financiamento de } \\
\text { agricultores. }\end{array}$ & $\begin{array}{l}\text { Embrapa: orientação } \\
\text { para produção; } \\
\text { Cooperativas: assistência } \\
\text { técnica, comercialização } \\
\text { do grão, e mobilização; } \\
\text { Petrobras: pagar pela } \\
\text { produção e assistência } \\
\text { técnica; e } \\
\text { Banco do Brasil: liberar } \\
\text { crédito para o plantio. }\end{array}$ & $\begin{array}{l}\text { SERGIPETEC: } \\
\text { Coordenação; } \\
\text { Embrapa: capacitação } \\
\text { dos agricultores; } \\
\text { Banco do Brasil: } \\
\text { Financiamento; e } \\
\text { COOPRASE: assistência } \\
\text { técnica. }\end{array}$ \\
\hline $\begin{array}{l}\text { Responsável pela } \\
\text { gestão }\end{array}$ & SERGIPETEC & SERGIPETEC & SERGIPETEC \\
\hline
\end{tabular}

Fonte: Elaborado pelo autor (2014).

Ao se analisar comparativamente as três instituições quanto à formação da rede, pode-se entender que as três cooperativas perceberam uma oportunidade para o desenvolvimento da agricultura familiar, e os motivos para participar da rede tinham por finalidade a eficiência. Observa-se, também, que as cooperativas reconhecem o SERGIPETEC como a organização que teve a iniciativa de formar a rede, cabendo à mesma instituição a coordenação, sendo vista como a instituição central da rede de cooperação em sua estrutura de governança com as demais instituições apoiadoras para execução das atividades planejadas. Percebe-se que o 
SERGIPETEC, a Embrapa, o Banco do Brasil e as cooperativas foram as instituições que fizeram parte do início das atividades da rede.

No Quadro 6 é apresentado o resumo da categoria analítica formas de cooperação nas três instituições por meio dos elementos de análise: relações formais e informais.

Quadro 6. Resumo da categoria tipos de relação

\begin{tabular}{|c|l|l|l|}
\hline \multicolumn{1}{|c|}{ Elementos } & \multicolumn{1}{c|}{ COOPERAFIR } & \multicolumn{1}{c|}{ COOPRASE } & \multicolumn{1}{c|}{ COOPATSUL } \\
\hline Relações formais & Petrobras & $\begin{array}{l}\text { Petrobras e Banco } \\
\text { do Brasil }\end{array}$ & Petrobras \\
\hline Relações informais & $\begin{array}{l}\text { SERGIPETEC, } \\
\text { SEBRAE, Embrapa, e e } \\
\text { uma cooperativa. }\end{array}$ & $\begin{array}{l}\text { SERGIPETEC, } \\
\text { Embrapa e } \\
\text { COPERAFIR. }\end{array}$ & $\begin{array}{l}\text { COOPRASE e } \\
\text { Embrapa }\end{array}$ \\
\hline
\end{tabular}

Fonte: Elaborado pelo autor com base em Smith, Carroll e Ashford (1995).

Observa-se que tanto relações formais como informais se estabeleceram na rede de cooperação, e que a Petrobras foi a instituição que estabeleceu relações formais com todas as cooperativas. Apenas a COOPRASE estabeleceu uma relação formal com o Banco do Brasil.

As instituições SERGIPETEC, SEBRAE, Embrapa, COOPRASE e COOPERAFIR foram citadas como organizações nas quais as relações informais foram estabelecidas, com destaque à Embrapa que foi citada por todas as organizações entrevistadas.

O quadro 7, a seguir, apresenta um resumo da categoria analítica benefícios nos três casos analisados com os elementos: Escala e Poder de Mercado, Acesso a Soluções e Capacitação, Aprendizagem e Inovação, Redução de Custos e Riscos, e Relações Sociais: 
Quadro 7. Elementos que representam benefícios da cooperação em rede

\begin{tabular}{|c|c|c|c|}
\hline Elementos & COOPERAFIR & COOPRASE & COOPATSUL \\
\hline $\begin{array}{l}\text { Escala e Poder } \\
\text { de Mercado }\end{array}$ & $\begin{array}{l}\text { Acesso ao crédito } \\
\text { bancário. }\end{array}$ & $\begin{array}{l}\text { Contratos de fornecimento de } \\
\text { produtos para programas de } \\
\text { alimentação escolar, programa de } \\
\text { aquisição de alimentos, ações de } \\
\text { assistência aos assentamentos, e } \\
\text { produção nos assentamentos. }\end{array}$ & $\begin{array}{l}\text { Credibilidade por } \\
\text { fornecer produtos } \\
\text { para a Petrobras. }\end{array}$ \\
\hline $\begin{array}{l}\text { Acesso a } \\
\text { Soluções e } \\
\text { Capacitação }\end{array}$ & $\begin{array}{l}\text { Fornecidas por } \\
\text { instituições } \\
\text { financeiras } \\
\text { conveniadas. }\end{array}$ & $\begin{array}{l}\text { Recursos financeiros para a } \\
\text { produção de produtos; } \\
\text { Profissionalização por meio da } \\
\text { troca de informações e capacitação } \\
\text { com instituições financeiras para } \\
\text { acesso ao credito e elaboração de } \\
\text { projetos. }\end{array}$ & $\begin{array}{l}\text { Participação de } \\
\text { curso no Banco do } \\
\text { Brasil sobre } \\
\text { elaboração de } \\
\text { projetos. }\end{array}$ \\
\hline $\begin{array}{l}\text { Aprendizagem e } \\
\text { Inovação }\end{array}$ & $\begin{array}{l}\text { Capacitação de } \\
\text { técnicos agrícolas } \\
\text { e cooperados. }\end{array}$ & $\begin{array}{l}\text { Visitas técnicas a agricultores para } \\
\text { orientá-los sobre melhores práticas } \\
\text { de produção, época de plantio, } \\
\text { adubação, tipos de sementes, } \\
\text { colheita e armazenamento. As } \\
\text { ações tinham por finalidade } \\
\text { aumentar a produção e reduzir os } \\
\text { desperdícios. }\end{array}$ & $\begin{array}{l}\text { Orientação dos } \\
\text { agricultores } \\
\text { familiares quanto a } \\
\text { melhor produção de } \\
\text { seus produtos. }\end{array}$ \\
\hline $\begin{array}{l}\text { Redução de } \\
\text { Custos e Riscos }\end{array}$ & $\begin{array}{l}\text { Redução de } \\
\text { custos com } \\
\text { logística e } \\
\text { contratos com os } \\
\text { cooperados. }\end{array}$ & $\begin{array}{l}\text { Otimização dos custos e melhor } \\
\text { utilização dos recursos. }\end{array}$ & $\begin{array}{l}\text { Ocorreu pela } \\
\text { necessidade de } \\
\text { interagir com } \\
\text { instituições } \\
\text { organizadas. } \\
\end{array}$ \\
\hline Relações Sociais & $\begin{array}{l}\text { Estabelecimento } \\
\text { de relações de } \\
\text { confiança com } \\
\text { instituições. }\end{array}$ & $\begin{array}{l}\text { Proximidade com alguns } \\
\text { representantes institucionais que } \\
\text { contribuíram para solucionar } \\
\text { problemas e almejar novos } \\
\text { negócios. }\end{array}$ & $\begin{array}{l}\text { Estabelecidas com } \\
\text { representantes das } \\
\text { cooperativas e dos } \\
\text { bancos. }\end{array}$ \\
\hline
\end{tabular}

Fonte: Elaborado pelo autor (2014).

Percebe-se que a Escala de Poder e Mercado proporcionou informações distintas nas três cooperativas com destaque ao acesso ao crédito bancário, reconhecimento como instituição que pode oferecer assistência técnica, fornecimento de produtos para programas de alimentação escolar e ações de assistência aos assentados e credibilidade por fornecer produtos a Petrobras. Quanto ao Acesso a Soluções e Capacitação, as três cooperativas apresentaram informações semelhantes, com destaque ao Banco do Brasil que ofereceu cursos sobre elaboração de projetos. Destaca-se a informação da COOPRASE quando diz que o resultado das capacitações foi o acesso a recursos financeiros para a produção de produtos e a profissionalização por meio da troca de informações.

As relações de cooperação proporcionaram aprendizagem e inovação nas três cooperativas estudadas que relataram a realização de visitas técnicas aos agricultores cooperados que tinham por finalidade a orientação dos produtores quanto às melhores formas de produção de seus produtos.

Os benefícios relativos à Redução de Custos e Riscos proporcionaram informações distintas nas três organizações estudadas. O representante da 
COOPERAFIR relatou que a redução de custos ocorreu com a melhora na logística de transporte de produtos e redução no número de contratos com os cooperados.

Já o representante da COOPRASE informou que a redução ocorreu com a necessidade de melhor utilização dos recursos, e a COOPATISUL informou que ocorreu pela necessidade de interagir com instituições organizadas.

A análise das Relações Sociais estabelecidas com representantes das organizações participantes da rede foi semelhante nas três organizações estudadas, que alegaram utilizar estas relações para solução de problemas, almejar novos negócios e discutir novos projetos e contratos convenientes às cooperativas.

\section{Considerações Finais}

O objetivo do estudo foi analisar como uma rede de cooperação contribuiu para a implantação e consolidação do PNPB e que benefícios gerou às cooperativas de agricultura familiar de Sergipe.

Inicialmente, percebeu-se que os motivos que levaram as cooperativas a participarem da rede foram semelhantes e sempre ligados ao desenvolvimento da agricultura familiar e da produção agrícolas nas respectivas regiões de atuação das cooperativas. Neste caso, o motivo apontado pelos representantes das cooperativas tem conformidade com o estudo de Oliver (1990) que atribui elementos responsáveis pela formação de redes, principalmente os ligados à necessidade e eficiência.

Quanto às relações estabelecidas com outras instituições participantes da rede, foi possível perceber que a única que não teve uma relação informal direta com a governança da rede foi a COOPATSUL. As demais tiveram relações semelhantes.

No caso das relações formais, as três cooperativas firmaram contratos com a Petrobras para ações de assistência técnica e venda da produção proveniente dos cooperados. Entretanto, a COOPERAFIR formalizou uma parceria com o Banco do Brasil que contribuiu para o acesso dos agricultores a crédito para a produção agrícola.

Segundo os entrevistados, um dos benefícios gerados pela rede foi a segurança que a contratualização proporcionou neste processo gerando escala de poder e de mercado e redução de custos e riscos. O resultado possui conformidade com o estudo de Balestrin e Vargas (2004) e de Ring e Van de Ven (1994) que destacaram as vantagens do equilíbrio entre os processos formais e informais nas relações de cooperação em redes.

Foi possível perceber que as relações de cooperação proporcionaram às cooperativas acesso a novos mercados, desenvolvimento da produção, capacitação das equipes técnicas e dos agricultores cooperados, além do estabelecimento de novas relações contratuais com diferentes instituições que, até então, não existiam.

É importante destacar que, independente da distinção entre os benefícios gerados por meio das relações de cooperação, os representantes das organizações 
estudadas destacaram que a rede foi importante para o desenvolvimento das cooperativas recém-formadas e para desmistificar visões equivocadas que instituições têm sobre organizações ligadas a movimentos sociais. Os resultados possuem conformidade com o estudo de Verschoore e Balestrin (2008) que apontaram cinco elementos que representam ganhos competitivos resultantes das Redes de Cooperação.

\section{REFERÊNCIAS}

ABRAMOVAY, Ricardo; MAGALHÃES, R. O acesso dos agricultores familiares aos mercados de biodiesel: parcerias entre grandes empresas e movimentos sociais. Londrina, 2007.

ALVES, J. N.; PEREIRA, B. A. D.; ANDRADE, T.; REIS, E. Confiança, aprendizagem e conhecimento nos relacionamentos interorganizacionais: diagnóstico e análise dos avanços sobre o tema. REAd, Porto Alegre: ed. 76, n. 3, set./dez., 2013, p. 709-737. Disponível em: < http://seer.ufrgs.br/index.php/read/article/view/43957/27605>. Acesso em: 16 mar. 2014.

ALVES-MAZZOTTI, A. J. Usos e Abusos dos Estudos de Caso. Cadernos de Pesquisa, v. 36, n. 129, set./dez., 2006, p. 637-651. Disponível em: <http://www.scielo.br/pdf/cp/v36n129/a0736129>. Acesso em: 12 out. 2012.

ARAGÃO, L. A.; LOPES, C. S.; ALVES JUNIOR, M. D. Redes de Cooperação de Pequenas e Médias Empresas: os Benefícios Estratégicos em Uma Rede de Supermercados. EnEO - Encontro de Estudos Organizacionais, 6. Anais..., p. 1-16, 2010. Florianópolis (SC), Brasil: ANPAD, 2010. Disponível em: <http://www.anpad.org.br/diversos/trabalhos/EnEO/eneo_2010/2010_ENEO39 2.pdf >. Acesso em 13 de maio de 2014.

BACHMANN, Reinhard; WITTELOOSTUIJN, Arjen van. Analysing InterOrganizational

Relationships in the Context of Their Business Systems - A Conceptual Framework for Comparative Research. Reihe Soziologie. Sociological Series 78, Editor: Beate Littig

Associate Editor: Gertraud Stadle, ISSN: 1605-8011, 2006. Disponível em: $<$ http://83.65.88.243/publications/soc/rs78.pdf>. Acesso em 11 de fevereiro de 2013.

BALESTRIN, Alsones; VARGAS, Lilia Maria. Evidencias Teóricas para a Compreensão das Redes Interorganizacionais. In: Encontro de Estudos Organizacionais, 2., 2002, Recife. Anais... Recife: Observatório da Realidade Organizacional : PROPAD/UFPE: ANPAD, 2002. 
BALESTRIN, Alsones; VERSCHOORE, Jorge Renato; REYES JUNIOR, Edgar. O Campo de Estudo sobre Redes de Cooperação Interorganizacional no Brasil. RAC, Curitiba, v. 14, n. 3, art. 4, maio/jun, 2010, p. 458-477.

BARBOSA, Agnaldo Sousa; SOUZA, Marco Aurélio Barbosa. Cooperação empresarial, capital social e desenvolvimento regional: $A$ experiência das aglomerações industriais de Franca e Birigui. Redes, Santa Cruz do Sul, v. 16, n. 2, p. 32 - 46, maio/ago. 2011. Disponível em: https://online.unisc.br/seer/index.php/redes/article/view/1880/1651. Acesso em: 13 de maio de 2014.

BORTOLASO, Ingridi; VERSCHOORE, Jorge Renato, ANTUNES JUNIOR, José Antônio Valle. Estratégias Cooperativas: avaliando a gestão da estratégia em redes de pequenas e médias empresas. Revista Brasileira de Gestão e Negócios. São Paulo, v. 14, n. 45, out./dez., 2012, p. 419-437.

BRASIL. Lei 11.097, de 13 de Janeiro de 2005a. Dispõe sobre a introdução do biodiesel na matriz energética brasileira; altera as Leis nos 9.478, de 6 de agosto de 1997, 9.847, de 26 de outubro de 1999 e 10.636, de 30 de dezembro de 2002; e dá outras providências. Diário Oficial [da] República Federativa do Brasil, Brasília, DF, 14 jan. 2005.2 Disponível em: <http://www.planalto.gov.br/ccivil_03/_ato2004-2006/2005/Lei/L11097.htm>. Acesso em: 03 dez. 2012.

BRASIL, Lei no 11.116, de 18 de maio de 2005b. Dispõe sobre o Registro Especial, na Secretaria da Receita Federal do Ministério da Fazenda, de produtor ou importador de biodiesel e sobre a incidência da Contribuição para o PIS/Pasep e da Cofins sobre as receitas decorrentes da venda desse produto; altera as Leis nos 10.451, de 10 de maio de 2002, e 11.097, de 13 de janeiro de 2005; e dá outras providências. Diário Oficial [da] República Federativa do Brasil, Brasília, DF, 19 maio 2005. p. 1-6. Disponível em: < http://www.receita.fazenda.gov.br/Legislacao/leis/2005/lei11116.htm>. Acesso em: 03 dez. 2012.

BRASIL, Ministério de Minas e Energia. Resolução $n{ }^{\circ} 3$, de 23 de setembro de 2005. Reduz o prazo de que trata o $\S 1^{\circ}$ do art. $2^{\circ}$ da Lei $n^{\circ} 11.097$, de 13 de janeiro de 2005, para o atendimento do percentual mínimo intermediário de dois por cento, em volume, cuja obrigatoriedade se restringirá ao volume de biodiesel produzido por detentores do selo "Combustível Social", instituído pelo Decreto $\mathrm{n}^{\circ}$ 5.297, de 6 de dezembro de 2004, e se iniciará em $1^{\circ}$ de janeiro de 2006, nos termos e condições estabelecidos nesta Resolução. Diário Oficial [da] República Federativa do Brasil, Brasília, DF, n. 187, 28 set. 2005. Seção 1, p. 3. Disponível em:

<http://www.mme.gov.br/mme/galerias/arquivos/conselhos_comite/CNPE/resol ucao_2005/Resolucao03.pdf >. Acesso em: 21 dez. 2012.

BRASIL, Ministério do Desenvolvimento Agrário (MDA). Instrução Normativa MDA n 01, de 19 de fevereiro de 2009. Dispõe sobre os critérios e procedimentos 
relativos à concessão, manutenção e uso do selo combustível social. Diário Oficial [da] República Federativa do Brasil, Brasília, DF, n. 37, 25 fev. 2009. Seção 1, p. 71-73.

Disponível em: http://portal.mda.gov.br/portal/saf/arquivos/view/biodisel/IN_01_19-022009_Concess\% C3\% A3o.pdf. Acesso em: 11 out. 2012.

BRASIL, Portaria no 60, de 06 de setembro de 2012. Dispõe sobre os critérios e procedimentos relativos à concessão, manutenção e uso do Selo Combustível Social. Diário Oficial [da] República Federativa do Brasil, Brasília, DF, 06 set. 2012. cap. 2, Seção 1, p. 1-25. Seção 1, p. 3. Disponível em: < http://www.lex.com.br/legis_23694594_PORTARIA_N_60_DE_6_DE_SETEMBRO _DE_2012.aspx>. Acesso em: 14 dez. 2012.

CAMPOS, Arnoldo Anacleto de, CARMELO, Edna de Cássia. Construir a diversidade da matriz energética: o biodiesel no Brasil. In: Biocombustíveis: a energia da controvérsia. São Paulo: Editora Senac, 2009.

CASTELLS, M. A era da informação: economia, sociedade e cultura - A sociedade em rede. São Paulo: Paz e Terra, 1999.

CASTRO, Marcos de; BULGACOV, Sergio; HOFFMANN, Valmir Emil. Relacionamentos Interorganizacionais e Resultados: Estudo em uma Rede de Cooperação Horizontal da Região Central do Paraná. $R A C$, Curitiba, v. 15, n. 1, art. 2, pp. 25-46, Jan./Fev. 2011. Disponível em: <http://www.scielo.br/pdf/rac/v15n1/v15n1a03.pdf>. Acesso em: 11 de fevereiro de 2013.

CHETTY, Sylvie; AGNDAL, Henrik. Role of inter-organizational networks and interpersonal networks in an industrial district. Regional Studies, v. 41, p. 1-13, 2007.

CRESWELL, J. Research design: Qualitative, quantitative, and mixed methods approaches. London: Sage, 2002.

EINSENHARDT, K. M. Building theories from case study research. Academy of Management Review. v. 14, n.4, p. 532-550, 1989.

GARCIA, Manoel Garcia. Governança em redes de empresas: o arranjo produtivo local do setor moveleiro da região metropolitana de São Paulo. Dissertação (Mestrado) - Apresentada ao Departamento de Administração do Instituto de Ciências Sociais da Universidade Paulista: São Paulo, 2008, $155 f$.

GONÇALVES, M. F.; EVANGELISTA, F. R. Os Descompassos do Programa Nacional de Produção e uso de Biodiesel (PNPB) no Nordeste. XLVI Congresso da Sociedade Brasileira de Economia, Administração e Sociologia Rural. Rio Branco Acre, 20 a 23 jul., 2008. 
NEUMAN, L. W. Social Research Methods: Qualitative and Quantitative Approaches. 3. ed. Boston: Allyn \& Bacon, Cap 2 -Dimension of Research 1997, p. 18-35.

PROVAN, Keith G.; FISH, Amy; SYDOW, Joerg. Interorganizational Networks at the Network Level: A Review of the Empirical Literature on Whole Networks. Journal of Management, Thousand Oaks, v. 33, p. 479-516, jun. 2007.

OLIVEIRA, Aline Lourenço de; REZENDE, Daniel Carvalho de; CARVALHO, Cleber Castro de. Redes Interorganizacionais Horizontais Vistas como Sistemas Adaptativos Complexos Coevolutivos: o Caso de uma Rede de Supermercados. $R A C$, Curitiba, v. 15, n. 1, art. 4, p. 67-83, jan./fev. 2011.

OLIVER, Christine. Determinants of inter-organizational relationships: integration and future directions. Academy of Management Review, v. 15, n. 2, p. 241-265, 1990.

RING, Peter Smith, \& VAN DE VEN, Andrew H. Developmental processes of cooperative interorganizational relationships. Academy of Management Review, 19(1): 90-118, 1994.

RUMYANTSEVA, M.; TRETYAK, O. What is a network: An overview of theoretical explanations of inter-firm cooperation; 19th Annual IMP Conference September 2003 Lausanne, Switzerland, 2003.

SAUNDERS, Mark; LEWIS, Philip; THORNILL, Adrian. Research Methods for Business Students. $4^{\mathrm{a}}$ ed. Harlow, England: Pearson Education, 2007. cap. 10

SMITH, Ken G.; CARROLL, Stephen J.; ASHFORD, Susan J. (1995). Intra- and interorganizational cooperation: toward a research agenda. Academy of Management Journal, 38, 7-23.

STAKE, R., E. Case Studies. In: DENZIN, N. K.; LINCOLN, Y. S. (Ed.) Handbook of Qualitave Research. London: Sage Publications, 1994.

VERSCHOORE, Jorge Renato; BALESTRIN, Alsones. Ganhos competitivos das empresas em redes de cooperação. Revista de Administração, São Paulo, v.1, n.1, art.2, jan./jun. 2008.

VIEIRA, José Nilton de Souza. A agroenergia e os novos desafios para a política agrícola no Brasil. In.: O futuro da indústria: biodiesel. Série Política Industrial, Tecnológica e de Comércio Exterior - 14. Brasília, 2006.

VITAL BRAZIL, O. A.; SOUZA, A. M.; SILVA, M. S. ; VAZ, V. H. S. Impactos da produção e uso de biodiesel no estado de Sergipe. In: Rio Oil \& Gas Expo and Conference 2008. Rio de Janeiro: IBP, 2008. 
YIN, R. K. Estudo de Caso: Planejamento e Métodos. Trad. Ana Thorell - $4^{\mathrm{a}} \mathrm{Ed}$. São Paulo: Bookman, 2010.

Submetido em 02/07/2013

Aprovado em 15/03/2015

\section{Sobre os autores}

Vitor Hugo da Silva Vaz

Mestre em Administração pela Universidade Federal de Sergipe - UFS. Desenvolve e coordena projetos pelo Parque Tecnológico de Sergipe.

Endereço: Av. Dr. Carlos Rodrigues da Cruz, 826, Capucho. 49081190 - Aracaju, SE - Brasil

E-mail: vitorhugovaz22@hotmail.com

\section{Maria Elena Leon Olave}

Professora adjunta do Departamento de Administração da Universidade Federal de Sergipe e Coordenadora do Programa de Pós-graduação em Administração - PROPADM/UFS.

Endereço: Cidade Universitaria Prof. José Aloísio de Campos- DAD- Sala 11, Jardim Rosa Elze. 49100000 - Aracaju, SE - Brasil 